lactam probably arises from isomerization rather than from lack of stereospecificity in the displacement reaction. Also the chloro- $\beta$-lactam $2 c$ reacts with thallium phthalimide, but the reaction is sluggish and only low yields of the product $3 a$ have so far been realized (5\%).

Acknowledgement. We thank the Swedish Board for Technical Development for financial support.

1. a. Johansson, N. G. and Åkermark, B. Acta Chem. Scand. 25 (1971) 1927; b. Johansson, N. G. Acta Chem. Scand. 27 (1973) 1417; c. Johansson, N. G. and Åkermark, B. Tetrahedron Lett. (1971) 4785; d. Åkermark, B., Byström, S., Florin, E., Johansson, N. G. and Lagerlund, I. Acta Chem. Scand. Ser. B. 28 (1974) 375.

2. Lewandowska, J. Unpublished results.

3. Bachi, M. D. and Goldberg, O. Chem. Com. mun. (1972) 319.

Received November 16, 1974.

\section{Tobacco Chemistry. 30. The Absolute Configuration of 11-Nor-8-hydroxy-9- drimanone, a Constituent of Greek Nicotiana tabacum $\mathbf{L}$.}

\section{ARNE J. AASEN and CURT R. ENZELL*}

Research Department, Swedish Tobacco Co., Box 17 007, S-104 62 Stockholm 17, Sweden

Schumacher and Vestal ${ }^{1}$ have recently reported 11-nor-8-hydroxy-9-drimanone** (1) as a new constituent of Turkish tobacco leaves but without elaborating on the chirality of its three asymmetric centres. The gross structure of this ketol indicates a genetic relationship with tobacco terpenoids of the drimane/labdane group or, although less likely, of the carotenoid group. ${ }^{2}$ Since all tobacco terpenoids of the labdane/drimane group possess the "normal" stereochemistry at the A/B-ring junction ( $5 \alpha-\mathrm{H}$, $10 \beta-\mathrm{CH}_{3}$ ) and this would not be expected in the case of carotenoid derived tobacco nor-isoprenoids, elucidation of the absolute configuration of the ketol (1), now isolated from Greek tobacco, would indicate the nature of its precursor(s).

** Nomenclature and stereochemistry as defined in Ref. 3.
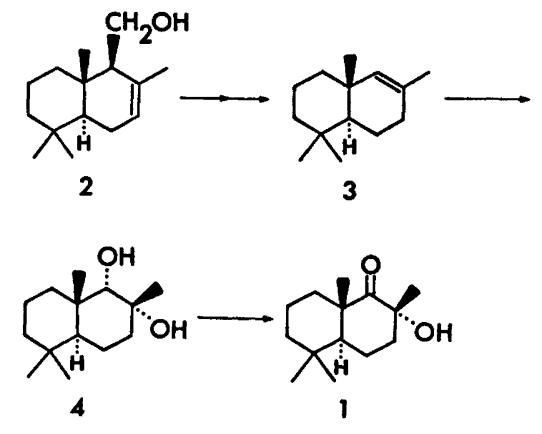

The absolute configuration of drimenol (2) has been determined through correlation with oleanolic and abietic acid, ${ }^{3}$ and it was envisaged that a stereospecific conversion of drimenol to 11-nor-8-hydroxy-9-drimanone (1) would unravel the chirality of the three asymmetric centres of the latter compound. This was accomplished using as starting material the olefin 3, which was prepared from drimenol (2) as previously described " by catalytic hydrogenation followed by oxidation to the corresponding saturated acid and subsequent decarboxylation using lead tetraacetate. Preferential attack by osmium tetroxide from the less hindered $\alpha$-side of the olefin (3) furnished the cis-diol (4) in good yield. Subsequent mild oxidation employing chromic acid in a twophase system ${ }^{5}$ gave the desired product, 11 nor-8-hydroxy-9-drimanone (1), which possesses a cedar-like, woody fragrance. 1 The synthetic and natural materials were found indistinguishable when comparing NMR, IR, MS and retention times on a capillary column (co-injection), and they exhibited rotatory powers of the same sign and magnitude. Since several syntheses of drimenol have been accomplished, ${ }^{6-10}$ its conversion, portrayed above, to 11-nor-8-hydroxy9-drimanone (1) formally represents a total synthesis of the latter.

Possessing the same absolute configuration as the previously detected tobacco terpenoids of the drimane/labdane group, ${ }^{2}$ it seems highly probable that the ketol $(1)$ is derived from representatives of this group, e.g. from 8,11drimandiol ${ }^{11}$ by a route similar to the present synthetic one or by direct oxidation of 9,11 didehydronorambreinolide. ${ }^{1}$

Experimental. NMR, IR, UV, and mass spectra were recorded on Varian XL-100, Digilab FTS-14, Beckman DB-2A and LKB 9000 instruments, respectively. Rotations were measured on a Perkin-Elmer 141 instrument.

11-Nor-8-hydroxy-9-drimanone $(1,4 \mathrm{mg}$ ) was isolated from a volatile, neutral fraction (B 5) of an extract obtained from $295 \mathrm{~kg}$ sun-cured Greek Nicotiana tabacum L.12 The separation of this fraction will be described elsewhere. ${ }^{13}[\alpha]^{20}$ $+39.5^{\circ}(589 \mathrm{mn}),+41^{\circ}(578),+50.5^{\circ}(546)$, $+124^{\circ}(436),+337^{\circ}$ (365) (c 0.29, $\left.\mathrm{CHCl}_{3}\right)$;

Acta Chem. Scand. B 28 (1974) No. 10 
NMR, IR, and mass spectra: see under synthetic 11-nor-8-hydroxy-9-drimanone.

11-Nor-8,9 $\alpha$-drimandiol (4). 11-Nor-8-drimene $(3,100 \mathrm{mg})^{4}$ dissolved in dry pyridine $(10 \mathrm{ml})$ was added to a cooled $\left(-30^{\circ} \mathrm{C}\right)$ solution of osmium tetroxide $(150 \mathrm{mg})$ in pyridine $(10 \mathrm{ml})$ and the mixture stirred for $3 \mathrm{~h}$ while the disappearance of the hydrocarbon was monitored by TLC. A solution of $\mathrm{NaHSO}_{3}(1.8 \mathrm{~g})$ in water $(30 \mathrm{ml}) /$ pyridine $(20 \mathrm{ml})$ was added and the solution stirred at room temperature for 20 min after which the mixture was diluted with water and extracted with $\mathrm{CH}_{2} \mathrm{Cl}_{2}$. The extract was washed with $\mathrm{H}_{2} \mathrm{SO}_{4}(5 \%)$, water, brine, dried, and evaporated leaving a slightly coloured oil. Chromatography on silica gel furnished 11-nor-8,9 $\alpha$-drimandiol $(4,87 \mathrm{mg})$ which crystallized on standing at $5{ }^{\circ} \mathrm{C}$; m.p. $58-59$ ${ }^{\circ} \mathrm{C}$; MS: $m / e 226\left(\mathrm{M}^{+\cdot} \cdot 12\right), 43$ (100), $95(86), 41$ $(84), 69(81), 123(73), 81(72), 138(65), 82$ (64), 71 (60), 137 (50), 55 (49), 109 (39), 67 (33), 96 (28), $84(28), 83$ (23), 57 (20), $196(20)$, 177 (19); $v_{\max }(\mathrm{KBr}): 3478$ (shoulder), 3400 (broad), 2949 (s), 2874 (s), 1456 (m), 1377 (m), $1360(\mathrm{w}), 1124(\mathrm{w}), 1092(\mathrm{w}), 1072(\mathrm{w}), 1056(\mathrm{~m})$, 1026 (w), 1012 (w), 994 (w), 978 (w), 960 (w), $955(w), 942(w), 895(w), 876(w), 828(w), 728$ $(\mathrm{w}) ;[\alpha]^{20}-11.6^{\circ}(589 \mathrm{~nm}),-18^{\circ}(578),-19.5^{\circ}$ $(546),-27.4^{\circ}(436),-46^{\circ}(365)\left(c 0.38, \mathrm{CHCl}_{3}\right)$; $\delta\left(\mathrm{CDCl}_{3}\right): 0.81(3 \mathrm{H}, \mathrm{s}), 0.89(3 \mathrm{H}, \mathrm{s}), 0.97$ (3 H, s), 1.37 (3 H, s), 2.30 (OH, broad s), 2.74 $(\mathrm{OH}, \mathrm{d}, J 2.5 \mathrm{~Hz}), 2.94$ (1 H, d, J ca. $2.5 \mathrm{~Hz}$ ), the signals at $\delta 2.30$ and 2.74 disappeared and the resonance at $\delta 2.94$ collapsed to a singlet on addition of $\mathrm{D}_{2} \mathrm{O}$.

11-Nor-8-hydroxy-9-drimanone (1). To a cooled (ice-bath) solution of the diol $4(43 \mathrm{mg})$ in ether $(10 \mathrm{ml})$ was added ten drops of the $\mathrm{CrO}_{3}$-solution described by Brown et al. ${ }^{5}$ After stirring for 30 min water was added and the mixture extracted with ether which was washed with $\mathrm{NaHCO}_{3}$, water, brine, dried, and evaporated leaving an oil (38 mg). Chromatography on silica gel yielded pure 11-nor-8-hydroxy-9. drimanone $(1,17 \mathrm{mg})$ which was indistinguishable from the natural ketol 1 (NMR, IR, MS, retention time, when co-injected on a capillary GC-column). MS: $m / e 224$ (M+• 22) 43 (100), 69 (86), $123(72), 41(64), 55(50), 95(50), 82(49)$, 109 (48), $67(46), 81(44), 71(43), 83$ (42), 163 (42), 125 (40), 68 (37), 196 (25); minor intensitydifferences were observed when compared with the spectrum recorded by Dr. Schumacher; ${ }^{14}$ $v_{\max }$ (film): 3485 (broad), 2932(s), 2870 (s), 1696 (s), $1466(\mathrm{~m}), 1393(\mathrm{~m}), 1380(\mathrm{~m}), 1371(\mathrm{~m}), 1343$ (w), $1245(\mathrm{~m}), 1175(\mathrm{~m}), 1163(\mathrm{~m}), 1142(\mathrm{~m})$, $1114(w), 1100(w), 1064(w), 1026(w), 1012$ $(\mathrm{w}), 992(\mathrm{~s}), 976(\mathrm{~m}), 949(\mathrm{~m}), 918(\mathrm{w}), 843(\mathrm{w})$, 842 , (w), 693 (w); lit. ${ }^{1} v_{\max }($ film): 3475,1690 , 1242 1160, 990; $[\alpha]^{20}+46^{\circ}(589 \mathrm{~nm}),+49.3^{\circ}$ $(578),+59^{\circ}(546),+142^{\circ}(436),+395^{\circ}(365)$ (c 0.3, $\left.\mathrm{CHCl}_{3}\right) ; \delta\left(\mathrm{CDCl}_{3}\right): 0.93(6 \mathrm{H}, \mathrm{s}), 1.18(3$ $\mathrm{H}, \mathrm{s})$, $1.41(3 \mathrm{H}, \mathrm{s}), 2.00-2.35(1 \mathrm{H}, \mathrm{m})$; lit. ${ }^{1}$ $\delta\left(\mathrm{CDCl}_{3}\right): 0.93(6 \mathrm{H}), 1.16(3 \mathrm{H}), 1.40(3 \mathrm{H})$.

Note added in proof. Dr. J. N. Schumacher (private communication) has confirmed our results by degrading 9,11-didehydronorambreinolide to 11-nor-8,9-drimandiol which exhibited the same optical activity as the corresponding diol derived from natural 11-nor-8-hydroxy-9-drimanone (1) by $\mathrm{LiAlH}_{4}$ reduction.

Acknowledgements. The authors are indebted to Miss Ann-Marie Eklund for skilful technical assistance, Professor H. H. Appel, Universidad Tecnica Federico Santa Maria, Valparaiso, for a generous gift of drimenol, and Dr. J. N. Schumacher, R. J. Reynolds Tobacco Co., Winston-Salem, for a copy of the mass spectrum of the title compound.

1. Schumacher, J. N. and Vestal, L. Tobacco Sci. 18 (1974) 43.

2. Aasen, A. J., Hlubucek, J. R. and Enzell, C. R. Acta Chem. Scand. In press, and ref. cited therein.

3. Appel, H. H., Brooks, C. J.W. and Overton, K. H. J. Chem. Soc. (1959) 3322.

4. Hlubucek, J. R., Aasen, A. J., Almqvist, S.-O. and Enzell, C. R. Acta Chem. Scand. $B 28$ (1974) 18.

5. Brown, H. C., Garg, C. P. and Lin, K.-T. J. Org. Chem. 36 (1971) 387.

6. Caliezi, A. and Schinz, H. Helv. Chim. Acta 32 (1949) 2556; 33 (1950) 1129; 35 (1952) 1637.

7. Stadler, P. A., Eschenmoser, A., Schinz, H. and Stork, G. Helv. Chim. Acta 40 (1957) 2191.

8. van Tamelen, E. E., Storni, A., Hessler, E. J. and Schwartz, M. J. J. Amer. Chem. Soc. 85 (1963) 3295.

9. Wenkert, E. and Strike, D. P. J.Amer. Chem. Soc. 86 (1964) 2044.

10. van Tamelen, E.E. and Hessler, E. J.Chem. Commun. (1966) 411.

11. Hlubucek, J. R., Aasen, A. J., Almqvist, S.-O. and Enzell, C. R. Acta Chem. Scand. B 28 (1974) 289.

12. Kimland, B., Aasen, A. J. and Enzell, C. R. Acta Chem. Scand. 26 (1972) 2177.

13. Aasen, A. J., Kimland, B., Hlubucek, J. R. and Enzell, C. R. To be published.

14. Schumacher, J. N. Private communication.

Received November 8, 1974.

Acta Chem. Scand. B 28 (1974) No. 10 